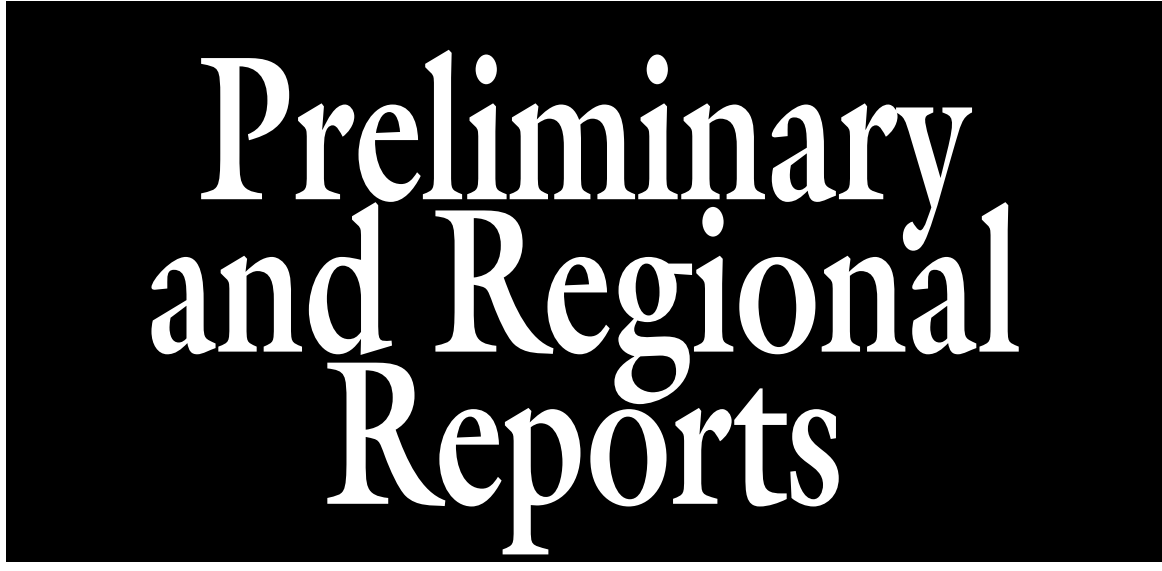

\section{Application of Microbubbles to Hydroponics Solution Promotes Lettuce Growth}

\author{
Jong-Seok Park ${ }^{1,2}$ and Kenji Kurata ${ }^{1}$
}

AdDitional INDEX wORDs. Lactuca sativa, macrobubbles, deep flow technique, culture

SUMMARY. We investigated the effects of microbubbles, generated by a swivelling microbubble generator in hydroponics nutrient solution, on the growth of leaf lettuce (Lactuca sativa). Twenty-four lettuce seedlings at the four- to five-leaf stage each were transplanted into two culture containers at $21 \pm 1^{\circ} \mathrm{C}$ (day) and $18 \pm 1^{\circ} \mathrm{C}$ (night) under fluorescent lamps that provided a photosynthetic photon flux of $173 \pm$ 18 and $171 \pm 16 \mu \mathrm{mol} \cdot \mathrm{m}^{-2} \cdot \mathrm{s}^{-1}$ averaged at eight points at the canopy level for microand macrobubbles conditions, respectively, during a photoperiod of $16 \mathrm{~h}$ per day. Seedlings were cultivated for 2 weeks in two deep flow technique (DFT) hydroponics culture systems in which micro- or macrobubbles were produced, respectively, by a microbubble aerator and aquarium aeration stones. The nutrient solution was maintained at a temperature of $22 \pm 1{ }^{\circ} \mathrm{C}$ during the experiment. Fresh and dry weights of the microbubble-treated lettuce were 2.1 and 1.7 times larger, respectively, than those of the macrobubble-treated lettuce. Although the reasons for growth promotion by microbubbles are still under investigation, we speculate that the larger specific surface area of the microbubbles and negative electronic charges on the microbubbles surfaces may promote growth because microbubbles can attract positively charged ions that are dissolved in the nutrient solution. These results indicate that microbubbles generated in a DFT hydroponics culture system can remarkably promote plant growth.

$\mathrm{M}$ icrobubble technology has been gathering much attention in many fields, including foam fractionation, food processing, purification processing of polluted water, and marine culture of oysters (Kodama et al., 2000; Ohnari and Tsunami, 2006; Takahashi, 2005). Successful applications of microbubbles to bioprocessing of polluted water and to aquaculture have been reported (Ohnari, 2007). Microbubbles are tiny gas bubbles

${ }^{1}$ Department of Bio-Environmental Engineering, The University of Tokyo, Bunkyo-Ku, Tokyo 113-8657, Japan

${ }^{2}$ Corresponding author. E-mail: ajspark@mail.ecc. u-tokyo.ac.jp. with a mean diameter of $50 \mu \mathrm{m}$ or less in water (Ohnari and Tsunami, 2006; Takahashi, 2005). One of the most significant characteristics of a microbubble is that it shrinks in water and ultimately collapses because it resides in water for a long time
(Zhang et al., 2007); in contrast, ordinary macrobubbles quickly rise and burst at the surface of water (Takahashi et al., 2003). Therefore, microbubbles are a highly efficient means of delivering dissolved gas into a solution. A crucial characteristic of the microbubble is that they are electrically negative charged ( $\zeta$ potential) on their surface (Ohnari and Tsunami, 2006; Takahashi, 2005); due to these charges, the bubbles do not attract each other and thereby get larger and attract positively charged materials. Because of these characteristics, microbubbles have significant potential to be used for a variety of practical purposes.

However, almost no information is available regarding how microbubbles affect vegetative plant growth in hydroponic culture systems. The objective of the present study was to examine the effect of microbubbles on the growth of leaf lettuce in a deep flow technique (DFT) hydroponics culture system. To understand the effects of microbubbles on plant growth, we compared lettuce treated with macrobubbles generated by aquarium aeration stones at a similar level of aeration.

\section{Material and methods}

Plant materials and culture conditions. The seeds of 'Coslettuce' leaf lettuce (Takii Seed Co., Tokyo) were sown in vermiculite and peat (1:1) mix and were placed in a part of a plant culture room $(4 \times 5.7$ $\mathrm{m})$ in which temperature was controlled with four air conditioners (SAP-V22B; SANYO Electric Co., Tokyo) at $21 \pm 1{ }^{\circ} \mathrm{C}$ (day) and $18 \pm$ $1 \quad{ }^{\circ} \mathrm{C}$ (night). Fluorescent lamps (CREAl-FPL55EX-L; Iwasaki Electric Co., Tokyo) provided a photosynthetic photon flux $(P P F)$ of $160 \pm$ $15 \mu \mathrm{mol} \cdot \mathrm{m}^{-2} \cdot \mathrm{s}^{-1}$ at the surface of the culture media. On day 14 after sowing, the seedling roots were detached

\begin{tabular}{llll}
\hline $\begin{array}{l}\text { Units } \\
\text { To convert U.S. to SI, } \\
\text { multiply by }\end{array}$ & U.S. unit & SI unit & $\begin{array}{l}\text { To convert SI to U.S., } \\
\text { multiply by }\end{array}$ \\
\hline 0.3048 & $\mathrm{ft}$ & $\mathrm{m}$ & 3.2808 \\
3.7854 & $\mathrm{gal}$ & $\mathrm{L}$ & 0.2642 \\
2.54 & inch $(\mathrm{es})$ & $\mathrm{cm}$ & 0.3937 \\
1 & $\mathrm{mmho} / \mathrm{cm}$ & $\mathrm{dS} \cdot \mathrm{m}^{-1}$ & 1 \\
28.3495 & $\mathrm{oz}$ & $\mathrm{g}$ & 0.0353 \\
1 & $\mathrm{ppm}$ & $\mathrm{mg} \cdot \mathrm{L}^{-1}$ & 1 \\
$\left({ }^{\circ} \mathrm{F}-32\right) \div 1.8$ & ${ }^{\circ} \mathrm{F}$ & ${ }^{\circ} \mathrm{C}$ & $\left(1.8 \times{ }^{\circ} \mathrm{C}\right)+32$
\end{tabular}


from the medium, washed, and wrapped in a urethane cube. Sixty seedlings were placed in hydroponics solution, half-strength Yamazaki nutrient solution, containing $45.4 \mathrm{mg} \cdot \mathrm{L}^{-1}$ nitrogen (41.9 mg. $\mathrm{L}^{-1}$ nitrate and $3.5 \mathrm{mg} \cdot \mathrm{L}^{-1}$ ammonium), $7.7 \mathrm{mg} \cdot \mathrm{L}^{-1}$ phosphorus, $78.1 \mathrm{mg} \cdot \mathrm{L}^{-1}$ potassium, $20.1 \mathrm{mg} \cdot \mathrm{L}^{-1}$ calcium, $6.1 \mathrm{mg} \cdot \mathrm{L}^{-1}$ magnesium, and $8.0 \mathrm{mg} \cdot \mathrm{L}^{-1}$ sulfur, and other micronutrients (Yamazaki, 1978). After 1 week, 24 seedlings at the four- to fiveleaf stage were selected for micro- and macrobubble treatments $(\mathrm{n}=12$ for each condition) and were transplanted with a planting distance of $13 \mathrm{~cm}$. They were cultured in the room for 2 weeks at $21 \pm 1{ }^{\circ} \mathrm{C}$ day and $18 \pm 1{ }^{\circ} \mathrm{C}$ night temperatures under fluorescent lamps (CREAl-FPL55EX-L, Iwasaki Electric Co.) providing a $P P F$ of $173 \pm$ 18 and $171 \pm 16 \mu \mathrm{mol} \cdot \mathrm{m}^{-2} \cdot \mathrm{s}^{-1}($ mean \pm $\mathrm{SD})$ averaged at eight points at the canopy level for micro- and macrobubble conditions, respectively, with a 16-h day and 8-h night photoperiod. For uniformity of light intensity, a shading net was set up between the light source and the lettuce. Plants grew in two culture containers $(46$ $\mathrm{cm}$ long $\times 66 \mathrm{~cm}$ wide $\times 33 \mathrm{~cm}$ high) filled with its full strength solution of $70 \mathrm{~L}$ in a DFT hydroponics culture system. A thermoregulating system with a heater (CTR-420; AGC Techno Glass Co., Chiba, Japan) and cooler (Coolpipe 150LF; Taitec Co., Saitama, Japan) continuously maintained the nutrient solution temperature at $22 \pm 1{ }^{\circ} \mathrm{C}$. Micro- and macrobubbles were continuously generated at the bottom of the containers throughout the experiment. We exchanged the position of the two culture containers for each experiment.

Micro- and MACrobubble GENERATION. Microbubbles were generated using a swiveling microbubble aerator $(3.5 \mathrm{~cm}$ diameter $\times 7.0 \mathrm{~cm}$ long; M2-MS/SUS; Nanoplanet Research Institute Co., Yamaguchi, Japan) with a pump (PMD-1521 B6E; Sanso Electric Co., Hyogo, Japan). Figure 1 shows a schematic diagram of the experimental setup used for this study. Water introduced into the aerator by the pump is spiraled up along the wall and down to an outlet along the center of the aerator. The centrifugal force caused by the circulation flow automatically introduces air from the gas inlet, and a vortex of air is formed along the center axis.

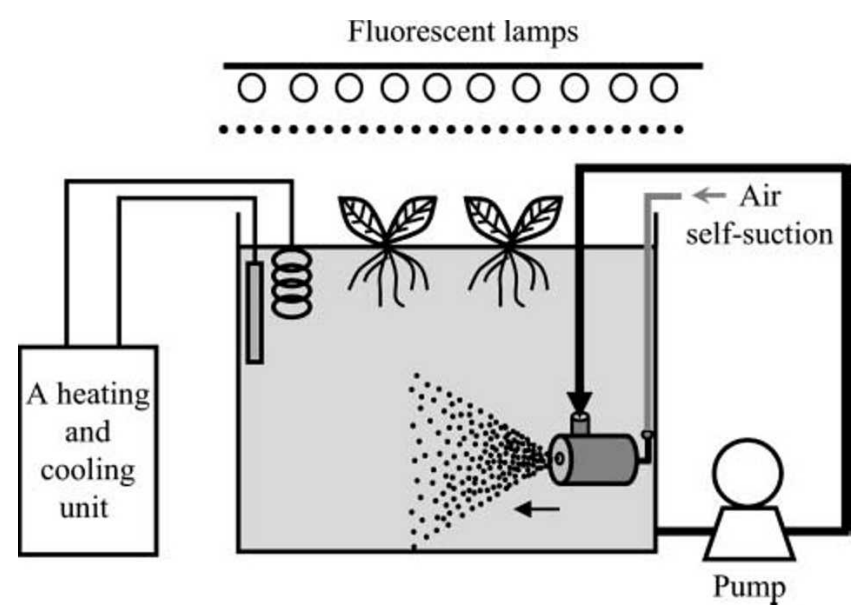

Fig. 1. Schematic diagram of deep flow technique hydroponics culture system with a microbubble aerator and a thermoregulator.
The gas is separated into fine bubbles at the outlet of the aerator by the strong shearing force of the dispersed water and the circulation power (Takahashi, 2005). Macrobubbles were generated through aquarium aeration stones by an air pump (MV70G; Enomoto Micro Pump, Tokyo). In both conditions, air was supplied at a rate of $1 \pm 0.1 \mathrm{~L} \cdot \mathrm{min}^{-1}$ throughout the cultivation period.

Measurement and statistical analysis. Dissolved oxygen (DO) concentration, electrical conductivity (EC), oxidation reduction potential (ORP), and $\mathrm{pH}$ of the nutrient solution were measured with a DO electrode (9520-10D with a D25 reading unit; Horiba, Kyoto, Japan), a EC meter (B-173, Horiba), a ORP electrode (9319-10D with a D25 reading unit, Horiba), and a $\mathrm{pH}$ electrode (6377-10D with a D2 I reading unit, Horiba), respectively, every $2 \mathrm{~d}$ throughout the cultivation period. Measured data showed only one selected replication because of not much difference in the values among the three replications. After the end of the culture period, fresh leaf weight, leaf number, leaf length, and leaf width were recorded. Leaves
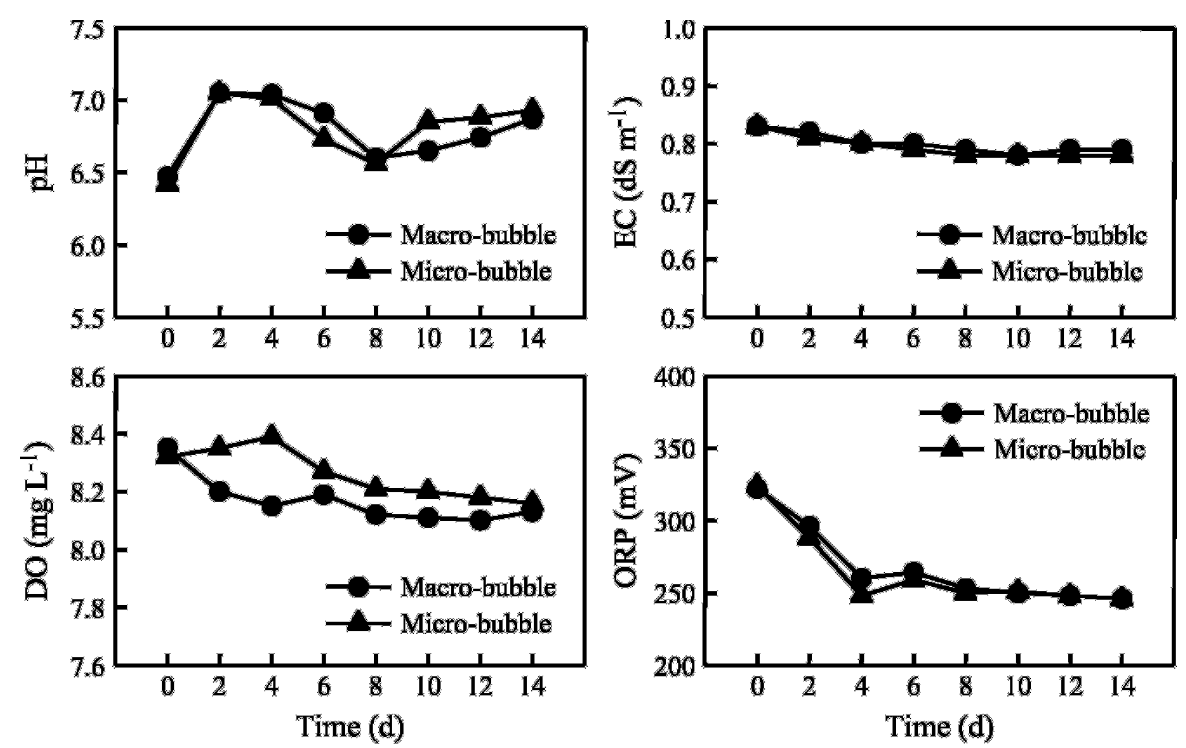

Fig. 2. Time course of $\mathrm{pH}$, electrical conductivity (EC), dissolved oxygen concentration (DO), and oxidation-reduction potential (ORP) in nutrient solution with generation of macro- and microbubbles for 2 weeks. Data show only one selected replication because of not much difference in the values among three replications; $1 \mathrm{mg} \cdot \mathrm{L}^{-1}=1 \mathrm{ppm}, 1 \mathrm{dS} \cdot \mathrm{m}^{-1}=1 \mathrm{mmho} / \mathrm{cm}$. 
and roots were placed in a dry oven (DX400; Yamato Scientific Co., Tokyo) at $66^{\circ} \mathrm{C}$ for $4 \mathrm{~d}$, and the dry weight was also measured. The experiment was repeated three times with completely randomized designs. Statistical analysis was subjected to analysis of variance followed by $t$ test at $P \leq 0.01$ using JMP software (SAS Institute, Cary, NC).

\section{Results and discussion}

The time course of $\mathrm{pH}, \mathrm{EC}, \mathrm{DO}$, and ORP in nutrient solution with generation of macrobubbles and microbubbles for 2 weeks was not much different among the three replications. EC, ORP, and $\mathrm{pH}$ in the nutrient solution did not differ between the micro- and macrobubble conditions at any time during the experiment (Fig. 2). However, DO in the microbubble condition was slightly higher than that in the macrobubble condition (Fig. 2), probably because of the excellent gas dissolution ability of microbubbles (Takahashi et al., 2003). Oxygen deficiency in the root zone can lead to poor root and plant performance and an increase in the infection of disease (Chérif et al., 1997). Research has found that aerial fresh weight of tomato (Solanum lycopersicum) plants cultivated under DO concentrations of 8.5 (ambient air saturated level), 20 , and $30 \mathrm{mg} \cdot \mathrm{L}^{-1}$ were not different among them, but showed a decrease in $40 \mathrm{mg} \cdot \mathrm{L}^{-1}$ conditions (Zheng et al., 2007). Tomato plant is more susceptible to pythium root rot (Pythium spp.) in a greenhouse culture if root zone oxygen drops below $2.8 \mathrm{mg} \cdot \mathrm{L}^{-1}$ (Chérif et al., 1997). Although the mean DO value in the microbubble treatment was $0.10 \mathrm{mg} \cdot \mathrm{L}^{-1}$ higher than that in the macrobubble treatment for 2 weeks, the difference in DO values would be predicted to have a negligible effect on plant growth in this DFT hydroponic culture system. All things considered, the solution's properties of $\mathrm{EC}, \mathrm{pH}$, ORP, and DO did not cause the difference in lettuce growth between two conditions.

Significant increases in growth were observed in the microbubble condition, where samples showed 2.1 times greater fresh leaf weight and 1.7 times greater dry leaf weight than the macrobubble samples (Fig. 3). Leaf number, leaf length,
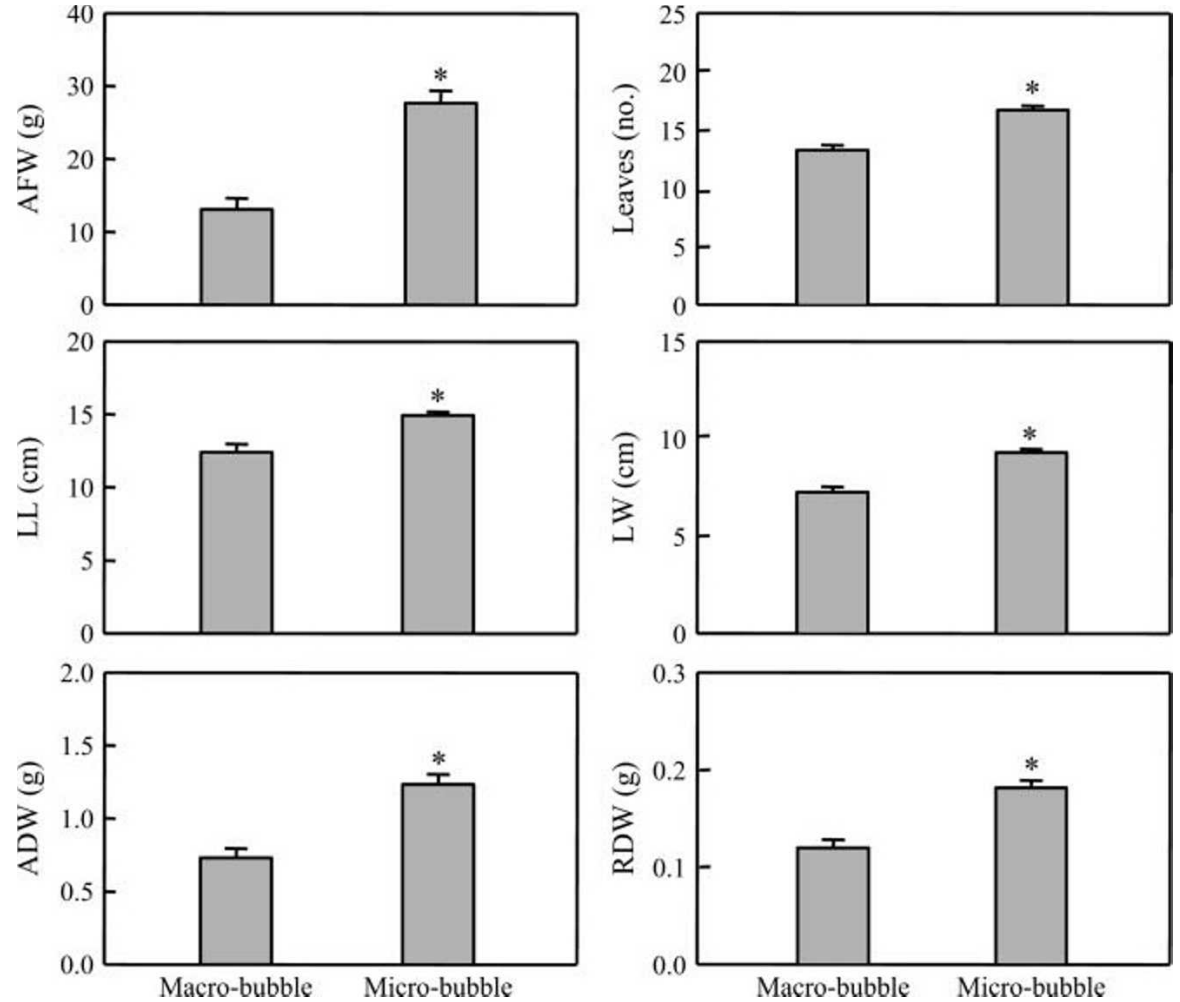

Fig. 3. Aerial fresh weight (AFW), leaves number, leaf length (LL), leaf width (LW), aerial dry weight (ADW), and root dry weight (RDW) per plant of leaf lettuce grown for 2 weeks in deep flow technique hydroponics culture system in which macro- and microbubbles were generated. Data represent means \pm SE. Means with an asterisk are significantly different by $t$ test at $P \leq 0.01(\mathrm{n}=36) ; 1 \mathrm{~cm}=0.3937$ inch, 1

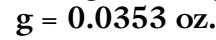

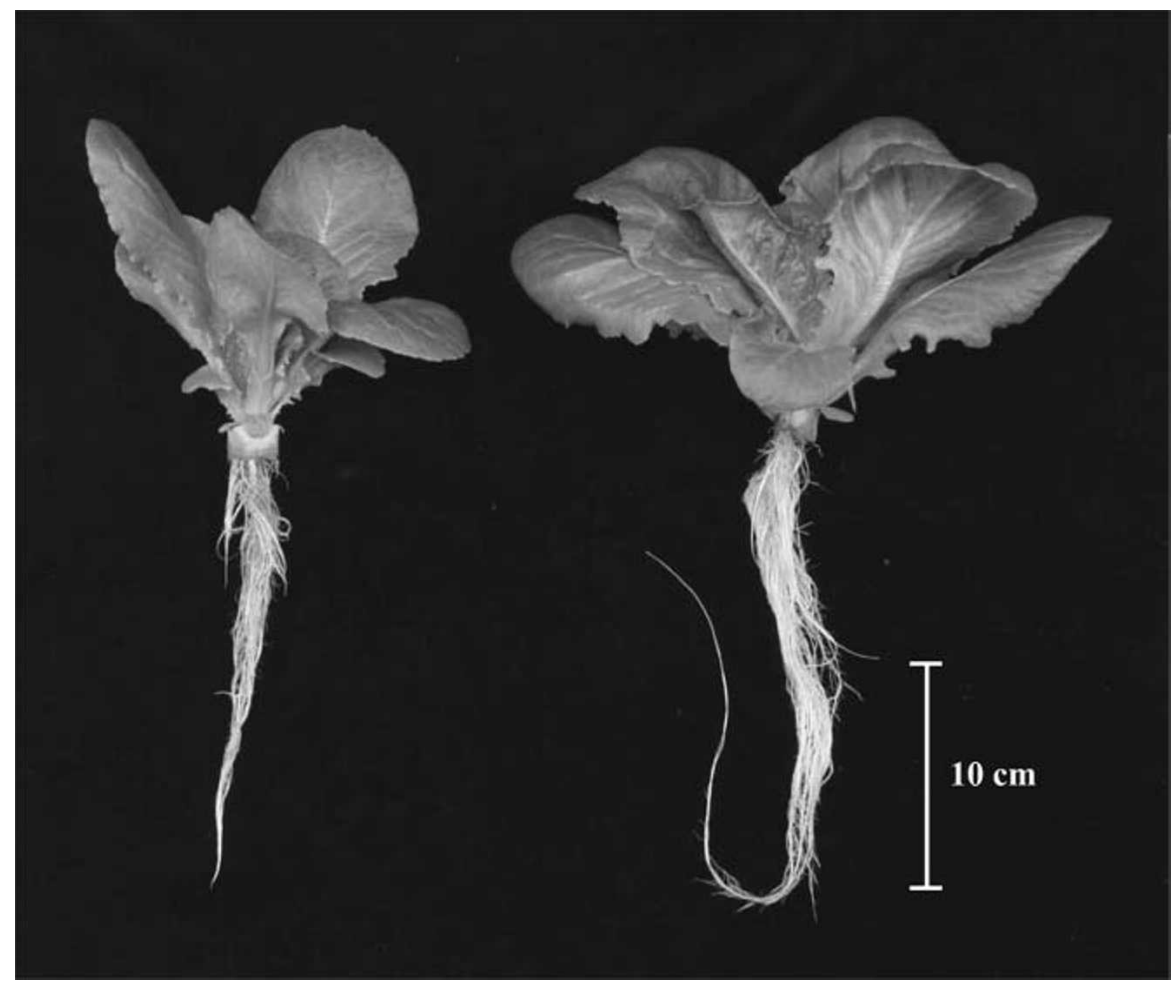

Fig. 4. Leaf lettuce grown for 2 weeks in a deep flow technique hydroponics culture system in which macrobubbles (left) or microbubbles (right) were generated in the nutrient solution; $1 \mathrm{~cm}=0.3937 \mathrm{inch}$. 
and leaf width of lettuce grown in the microbubble condition were also significantly higher (Fig. 3). A visible difference in aerial growth was observed $4 \mathrm{~d}$ after the start of the bubble generation. Although EC, ORP, pH, and DO did not differ, remarkably, promoted roots were observed in the microbubble condition (Fig. 4). This finding was consistent with a growth increase observed when water hyacinth (Eichornia crassipes) roots were treated with microbubbles, in that case for processing of polluted water in a pond (Ohnari, 2007). Thus, microbubbles generated in a DFT hydroponic culture system promoted root and shoot growth.

Although the reasons for growth promotion by the microbubbles are still under investigation, one of the possibilities is the larger specific surface area of microbubbles when compared with macrobubbles. Numerous microbubbles adhered to the root. This seems to positively stimulate root growth by supplying oxygen directly to the surface of roots. Neg- ative electronic charges on microbubbles surface may help roots absorb nutrient salts because microbubbles can attract positively charged ions that are dissolved in the nutrient solution, such as calcium, magnesium, potassium, and ammonium (Takahashi, 2005).

In conclusion, the advantage of using microbubbles was demonstrated in a DFT hydroponics culture system, remarkably promoting lettuce growth. Further study will be required to elucidate the relationship between the specific properties of microbubbles and plant root growth.

\section{Literature cited}

Chérif, M., Y. Tirilly, and R.R. Bélanger. 1997. Effect of oxygen concentration on plant growth, lipid peroxidation, and receptivity of tomato roots to pythium under hydroponic conditions. Eur. J. Plant Pathol. 103:255-264.

Kodama, Y., A. Kakugawa, T. Takahashi, and H. Kawashima. 2000. Experimental study on microbubbles and their applicability to ships for skin friction reduction. Int. J. Heat Fluid Flow 21: 582-588.

Ohnari, H. 2007. Maikuro baburu gijutsu no konnichi teki kadai. Kagaku Kōgaku 71:154-159. (in Japanese).

Ohnari, H. and Y. Tsunami. 2006. Maikuro baburu no hassei kikou to shūshuku tokusei. Mizu Kōgaku Ronbun Shū 50:1345-1350. (in Japanese).

Takahashi, M. 2005. Y Potential of microbubbles in aqueous solutions: Electrical properties of the gas-water interface. J. Phys. Chem. B 109:21858-21864.

Takahashi, M., T. Kawamura, Y. Yamamoto, H. Ohnari, S. Himuro, and H. Shakutsui. 2003. Effect of shrinking microbubbles on gas hydrate formation. J. Phys. Chem. B 107:2171-2173.

Yamazaki, K. 1978. Yōeki saibai zenpen. Hakuyūsha, Tokyo. (in Japanese).

Zhang, X.H., A. Khan, and W.A. Ducker. 2007. A nanoscale gas state. Phys. Rev. Lett. 98:136101.

Zheng, Y., L. Wang, and M. Dixon. 2007. An upper limit for elevated root zone dissolved oxygen concentration for tomato. Scientia Hort. 113:162-165. 